\title{
Highly Stable Regeneration from Long-term Cultures of Japanese Persimmon Callus
}

\author{
Mihoko Tamura, Ryutaro Tao, and Akira Sugiura \\ Laboratory of Pomology, Faculty of Agriculture, Kyoto University, Kyoto \\ 606, Japan
}

Additional index words. Diospyros kaki, subculturing, organogenesis

Japanese persimmon (Diospyros kaki L.) has been successfully regenerated from callus cultures (Tao and Sugiura, 1992; Tao et al., 1988, 1992), but callus that had been in culture for a relatively short time was used in these reports. This paper describes highfrequency adventitious bud formation from callus cultures maintained for more than 4 years.

As described earlier (Tao et al., 1988), callus cultures were initiated from leaf primordia of 'Jiro' Japanese persimmon dissected from dormant winter buds of a tree more than 30 years old. Explants were placed on modified Murashige and Skoog (MS) medium (Murashige and Skoog, 1962) with $\mathrm{NH}_{4} \mathrm{NO}_{3}$ and $\mathrm{KNO}_{3}$ reduced to half the original strength, supplemented with $10 \mu \mathrm{M}$ zeatin and $1 \mu \mathrm{M} 3$-indoleacetic acid (IAA). The initiated calli were maintained by subculturing onto the same fresh medium every 6 weeks. After 0 (6 weeks of culture) to 34 subcultures (210 weeks of culture), the calli were subdivided and transferred onto differentiation medium (Tao et al., 1992) consisting of MS medium supplemented with 10 $\mu \mathrm{M}$ zeatin and $0.1 \mu \mathrm{M}$ IAA to induce adventitious buds. Single callus clumps, each weighing $\approx 1.50 \mathrm{mg}$, were each placed in a separate test tube containing $20 \mathrm{ml}$ of the differentiation medium. The calli forming adventitious buds were determined macroscopically after 6 weeks of culture. For each subculture, there were 75 explants consisting of three subsamples of 2.5 explants each. Statistical analysis of the percentage of explants forming adventitious buds vs. the number of subcultures was performed by quadratic regression analysis, with each subsample treated as an individual point.

Received for publication 3 Oct. 1991. Accepted for publication 27 Apr. 1992. The cost of publishing this paper was defrayed in part by the payment of page charges. Under postal regulations, this paper therefore must be hereby marked $a d$ vertisement solely to indicate this fact.
All media contained $0.8 \%(\mathrm{w} / \mathrm{v})$ agar (Wako Pure Chemicals Co., Tokyo) and 3\% $(\mathrm{w} / \mathrm{v})$ sucrose. The $\mathrm{pH}$ of the media was adjusted to 5.7 to 5.8 before autoclaving at $121 \mathrm{C}$ and $120 \mathrm{kPa}$ for $1.5 \mathrm{~min}$. Cultures were maintained at $28 \mathrm{C}$ in darkness for callus growth or under a 12-h.day ${ }^{-1}$ photoperiod with a light intensity of $60 \mu \mathrm{mol} \cdot \mathrm{m}^{-2} \cdot \mathrm{s}^{-1}$ provided by cool-white fluorescent lamps for adventitious bud formation.

After no subculture and one subculture, the calli showed low organogenetic potential, with only $10 \%$ to $20 \%$ of calli forming adventitious buds (Fig. 1). The regression curve indicates that the percentage of adventitious bud formation peaked at 24 subcultures. The increasing organogenetic potential during the initial period of culture may be due to physiological changes related to rejuvenation. Compared with adult materials, juvenile explants taken from young plants or embryos grow vigorously in vitro and have higher organogenetic potential (Howard et al., 1989a, 1989b; Yokoyama and Takeuchi, 1988).

Organogenetic capacity of the calli declined slightly after 24 subcultures (Fig. 1). However, $>65 \%$ of the calli formed adventitious buds even after 34 subcultures. Further, the percentage of calli forming buds after 10 to 34 subcultures always exceeded $50 \%$. Such a high capacity of adventitious bud formation after repeated subcultures suggests that no change in ploidy occurred in the calli, because loss of regenerative ability has been correlated with a change in ploidy in cultured cells (Ogura, 1976; Sutter and Langhans, 1981; Torrey, 1967; Zagorska et al., 1974). Although investigations on chromosomal variations and field performance of the regenerated plants are needed, the callus cultures we described can serve as a valuable cell source for genetic manipulation and protoplast isolation (Tao et al., 1991).

\section{Literature Cited}

Howard, B.H., O.P. Jones, and J. Vasek. 1989a. Long-term improvement in the rooting of plum

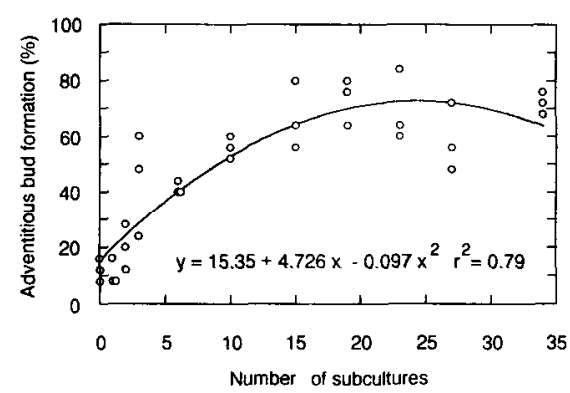

Fig. 1. Percentage of adventitious bud formation from callus cultures of Japanese persimmon in response to culture period. Each point represents the data from 25 explants.

cuttings following apparent rejuvenation. J. Hort. Sci. 64:147-156.

Howard, B.H., O.P. Jones, and J. Vasek. 1989b. Growth characteristics of apparently rejuvenated plum shoots. J. Hort. Sci. 64:157-162.

Murashige, T. and F. Skoog. 1962. A revised medium for rapid growth and bioassays with tobacco tissue culture. Physiol. Plant. 15:473497.

Ogura, H. 1976. The cytological chimeras in original regenerates from tobacco tissue cultures and in their offsprings. Jpn. J. Genetics 51:161174

Sutter, E. and R.W. Langhans. 1981. Abnormalities in Chrysanthemum regenerated from long term cultures. Ann. Bot. 48:559-568.

Tao, R., H. Murayama, K. Moriguchi, and A. Sugiura. 1988. Plant regeneration from callus cultures derived from primordial leaves of Japanese persimmon. HortScience 23:1055-1056.

Tao, R. and A. Sugiura. 1992. Adventitious bud formation from callus cultures of Japanese persimmon: Effect of growth regulators, explant origin, and genotype. HortScience 27:259-261.

Tao, R., M. Tamura, K. Yonemori, and A. Sugiura. 1991. Plant regeneration from callus protoplasts of adult Japanese persimmon (Diospyros kaki L.). Plant Sci. 79:119-125.

Tao, R., K. Yonemori, and A. Sugiura. 1992. High frequency plant regeneration from callus cultures derived from primordial leaves of adult Japanese persimmon aid protoplast isolation from those callus lines. Acta Hort. 300:251-254.

Torrey, J.G. 1967. Morphogenesis in relation to chromosomal constitution in long-term plant tissue cultures. Physiol. Plant. 20:265-275.

Yokoyama, T. and M. Takeuchi. 1988. Relationship between ontogenetic age and bud formation from leaf segments in Japanese persimmon, Diospyros kaki, Thunb. Plant Tissue Cult. Lett. 5:6-10.

Zagorska, N.A., Z.B. Shamina, and R.G. Butenko. 1974. The relationship of morphogenetic potency of tobacco tissue culture and its cytogenetic features. Biol. Plant. (Prague) 16:262274. 